\title{
Analysis of factors that may affect the enzymatic profile of gingival crevicular fluid: sampling technique, sequential sampling and mode of data presentation
}

\author{
Arzu Özkavaf, Hamit Aras, Cenk B. Huri, Nermin Yamalık, Asuman Kılınç§, \\ Kamer Kılınç§ and Feriha Çağlayan \\ Departments of Periodontology and ${ }^{\S}$ Biochemistry, Faculty of Dentistry and Faculty of Medicine, \\ University of Hacettepe, Ankara-Turkey
}

(Received 24 August 2000 and accepted 8 February 2001)

\begin{abstract}
To evaluate the possible effect of sampling technique and sequential sampling on gingival crevicular fluid (GCF) volume and myeloperoxidase (MPO) activity, 14 patients presenting at least two symmetrical maxillary sites with mild/moderate periodontitis were selected. Two sites in each individual were sequentially sampled using either the deepintracrevicular or orifice technique. Spectrophotometrically determined MPO levels were presented either as total MPO activity or MPO concentration. Although the clinical periodontal status of the $\mathbf{2 0}$ sampling sites were similar, the deep-intracrevicular technique regularly provided larger GCF volumes. With both techniques, the last samples contained the highest GCF volume. During sequential orifice sampling, GCF volume was relatively more stable. In general, a depletion of MPO activity was observed with sequential sampling performed with either of the techniques. Depletion of MPO did not replenish to baseline levels at the end of the 10 -min sequential sampling. Although MPO activity showed a general reduction during sequential orifice sampling with both modes of data presentation, total MPO activity and MPO concentration did not match with the deepintracrevicular technique. Due to the potential of affecting GCF volume/composition, the selection of sampling technique seems to be a critical methodological decision in GCF-profile studies, primarily during
\end{abstract}

Correspondance to Dr. Nermin Yamalık, Department of Periodontology, Faculty of Dentistry, University of Hacettepe, 06100 Ankara-Turkey

Phone: 903123127692 Fax: 903123104440 sequential sampling. In GCF-profile studies, mode of data presentation should also be considered. (J. Oral Sci. 43,41 - 48,2001 )

Key word: Gingival crevicular fluid; myeloperoxidase; methodology.

\section{Introduction}

The vast majority of gingival crevicular fluid (GCF) related studies have used different sampling techniques, sampling times and data presentations. A methodological standardization seems to be necessary to overcome the discrepancy between results (1-3).

Analysis of GCF collected with paper strips is currently the most preferred method, but a consensus does not exist concerning the extension of the strips within the crevice. Studies are available where strips are inserted deep at the base $(1,4-6)$, left of the entrance $(7-10)$ or placed to a defined depth (11-13). However, the reason for a preference for a certain depth of strip placement is either ignored or not mentioned. Since an early study of Egelberg and Attstrom (14), the choice of sampling technique is still likely to be done arbitrarily. Preferred sampling time is also not standardized and varies from seconds to several minutes $(1,4-7,12,13)$. Although a prolonged sampling time extending beyond 5 minutes is generally avoided, a reliable sampling time-range has not been defined. Thus, although GCF is considered to be related to mechanical irritation, the possible effect of the depth of strip placement and the duration of sampling time should be taken into account $(1,9,10,14)$. 
The appropriate GCF samples to analyze is another methodological point of debate $(4,9,13,15,16)$. While some authors prefer to perform laboratory analysis on the first (rGCF) samples $(6,13,15,17)$, others discard the first samples based on a consideration that rGCF reflects a static status within the crevice $(4,16)$.

The ideal mode of data presentation is also debatable $(2-4,6)$. Although most GCF components are presented as concentration, due to certain limitations, validity of this mode of data presentation is becoming more questionable everyday $(2,3)$. Thus, data presentation based on a standardized GCF sampling time is suggested $(2,8,18$ 20).

All of these methodological concerns of debate seem to be reasonable because they concern the risk of affecting the actual GCF profile. Therefore, studies conducted to evaluate the effect of certain methodological designs on GCF profile seem to be valuable for a better understanding of the biological features of GCF and also for the establishment of a standard methodology.

The aim of the present study was to evaluate the possible effect of the orifice and deep-intracrevicular sampling techniques and sequential sampling on GCF volume and myeloperoxidase (MPO) activity, an enzyme found in azurophilic granules of PMNs and that is involved in antibacterial activity together with $\mathrm{H}_{2} \mathrm{O}_{2}$ and halides $(21,22)$. Also, the validity of two modes of data presentation, total MPO activity and MPO concentration, were considered.

\section{Materials and Methods \\ Clinical studies}

Subject/sampling site selection: A total of 14 periodontally diseased patients (7 female and 7 male) with a mean age of $34.9 \pm 2.68$ were selected according to the following criteria; 1) no history of any systemic diseases, 2) no history of antibiotics and/or antiinflammatory drugs use or any periodontal treatment within the past 3 months, and 4) presenting at least two symmetrical maxillary sites with probing depth $(\mathrm{PD}) \geq$ $4 \mathrm{~mm}$, gingival index (GI) (23) $\geq 2$ and moderate alveolar bone loss. To avoid contamination with saliva, only maxillary sites were included. To standardize the possible effect of clinical periodontal status on GCF volume, symmetrical sites with similar periodontal status in each individual were sampled. In cases where multiple sites fulfilled the above criteria $(n=6)$, GCF sampling was performed at these multiple sites. Thus, a total of 40 maxillary sites ( 20 sites for the orifice technique, 20 sites for the deep-intracrevicular technique) in 14 patients were selected and at each sampling site GI scores and PD were recorded. To eliminate any volumetric change, samples were obtained before clinical measurements. All GCF samples were obtained between $8 \mathrm{am}-10 \mathrm{am}$. The patients were informed about the experimental design and consents were obtained.

Sampling of GCF: In each patient, GCF samples from the selected 2 sites were obtained either by the deepintracrevicular technique or the orifice technique. A total of 20 symmetrical sites fulfilling the above criteria were sampled. Two symmetrical sites in each patient were randomly selected for the orifice and the deepintracrevicular techniques. The sampling area was isolated with cotton rolls and supragingival plaque was eliminated. After gentle air drying, GCF was collected by use of standardized paper strips*. For the deep-intracravicular technique, strips were inserted into the base of the pocket until a slight resistance was felt (24). After the 1st, 2nd, 3rd and 4th deep-intracrevicular samples were collected at one minute intervals, an additional 6-minutes was waited before the collection of the 5 th sample. Thus, total time of sequential sampling at each site was approximately 10 minutes (10). For the orifice method (11), strips were inserted $1 \mathrm{~mm}$ into the pocket in the symmetrical site and the same sequential sampling was performed. Sampling time was 5 seconds for all samples. Samples with evidence of gingival bleeding were excluded. In order to eliminate the risk of evaporation, strips were immediately transported to previously calibrated Periotron $8000^{\dagger}$ for volume determination. Next, each sample was placed in a sterile, firmly wrapped Eppendorf tube and stored at $-20^{\circ} \mathrm{C}$ until the day of laboratory analysis.

\section{Laboratory studies}

Determination of MPO activity: MPO activity of GCF was measured using the spectrophotometric MPO assay (25) that is a modification of the method reported by Suzuki et al. (26). GCF MPO activity could only be determined after extraction with hexadecyltrimethyl ammonium bromide (HETAB) solution. Thus, the assay mixture ( $1 \mathrm{ml}$ final volume) consisted of $80 \mathrm{mM}$ phosphate buffer (pH 5.4), 1.6 mM synthetic substrate tetramethyl benzidine (TMB), $0.5 \%$ HETAB, $1 \mathrm{mM} \mathrm{H}_{2} \mathrm{O}_{2}$ and $0.1 \mathrm{ml}$ of GCF extract. The reaction was initiated by the addition of $\mathrm{H}_{2} \mathrm{O}_{2}$ and the rate of TMB oxidation was followed at $37^{\circ} \mathrm{C}$ using a recording spectrophotometer (Beckman Model 25). Considering the initial and linear phase of the reaction, the absorbance change per minute was calculated. One unit of enzyme activity was expressed as the amount of the enzyme producing one absorbance change per minute under assay conditions. MPO activity was expressed as 'total enzyme activity' and 'enzyme concentration.' 
Enzyme concentration stands for the MPO activity per microliter of GCF, and total enzyme activity refers to the total MPO activity collected onto the paper strips in 5 seconds.

\section{Statistical analysis}

$T$-tests for independent samples were used for comparison of the orifice and deep-intracrevicular techniques regarding mean PD, mean GI scores, GCF volume, MPO concentration and total MPO activity. Within group comparisons were made by $t$-test for dependent samples. Correlations between MPO concentration and total MPO activity, and between GCF volume and MPO activity were analyzed by simple correlation analysis (27).

\section{Clinical findings}

\section{Results}

Clinical periodontal status: The mean PD of the sampling area selected for orifice technique was $4.63 \pm 0.17 \mathrm{~mm}$ and the mean GI score was $1.8 \pm 0.16$. The mean PD of the sampling area selected for the deep-intracrevicular technique was $4.65 \pm 0.13 \mathrm{~mm}$ and the mean GI score was $1.75 \pm 0.14$. The difference between the mean $\operatorname{PD}(t=0.115$, $P=0.909)$ and GI $(t=0.237, P=0.814)$ scores for the orifice and deep-intracrevicular GCF sampling sites was not significant $(P>0.05)$.

$G C F$ volume: The mean GCF volumes during sequential sampling with two sampling techniques and actual $t$ and $\mathrm{p}$ values are given in Table 1. For all of the samples, the deep-intracrevicular technique provided more GCF volume than the orifice technique and this difference was statistically significant for all of the 5 repeated samples $(P<0.05)$. GCF volume was affected (increased) by sequential sampling with both sampling techniques. For both of the techniques, the 5th samples provided the highest GCF volume. While for the orifice technique, the only significant difference was observed between the first and the last samples, for the deep-intracrevicular technique, volumetric increases in the $2 \mathrm{nd}$, 3rd and 5th samples were found to be significant $(P<0.05)$ (Fig. 1).

Correlations between GCF volume and clinical parameters: Significant correlations between mean GI GCF volume and mean PD-GCF volume were not observed $(P>0.05)$.

\section{Laboratory findings}

$M P O$ concentration: Descriptive statistical data regarding GCF MPO concentrations and actual $t$ and $p$ values are given in Table 2. For the orifice method, there was a general tendency for GCF MPO concentrations to decrease throughout 5 repeated samples. When compared to the

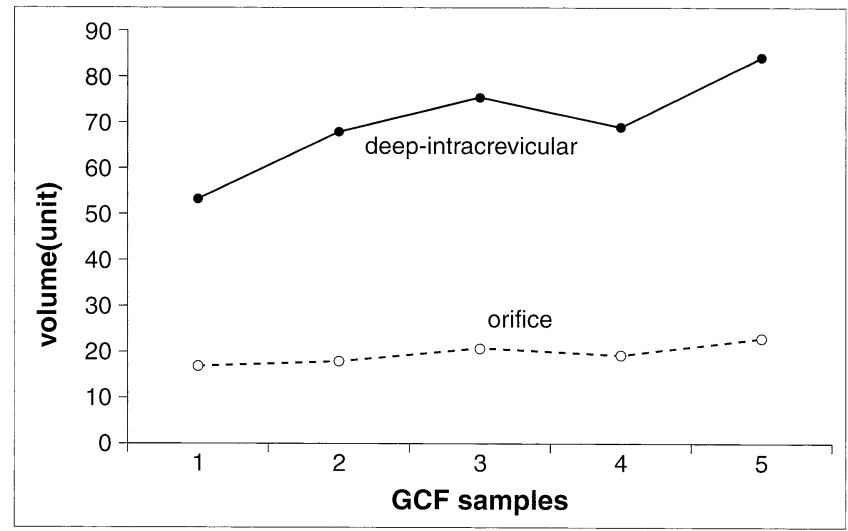

Fig. 1 Mean gingival crevicular fluid volume throughout sequential sampling.

Table 1 Descriptive statical data regarding mean gingival crevicular fluid volume with sequential orifice or deep-intracrevicular sampling(U).

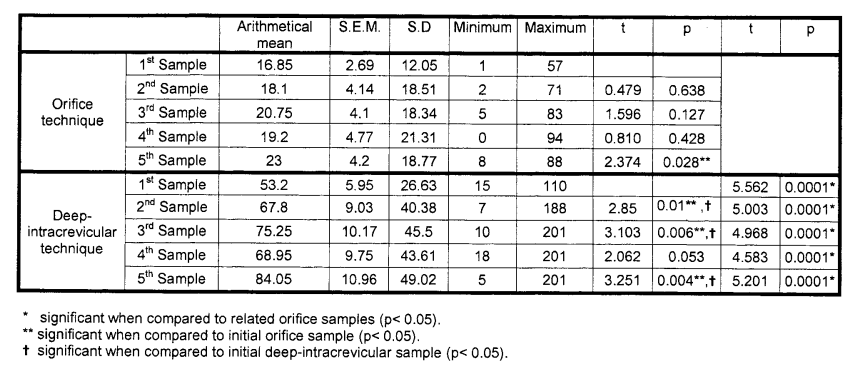

initial samples. significantly lower MPO concentrations were observed in the $3 \mathrm{rd}, 4$ th and 5 th samples $(P<0.05)$. For the deep-intracrevicular method, MPO concentration presented no significant differences throughout sequential sampling $(P>0.05)$. The difference between the orifice and the deep-intracrevicular technique regarding GCF MPO concentration was not significant in any of the repeated samples $(P>0.05)$ (Fig. 2).

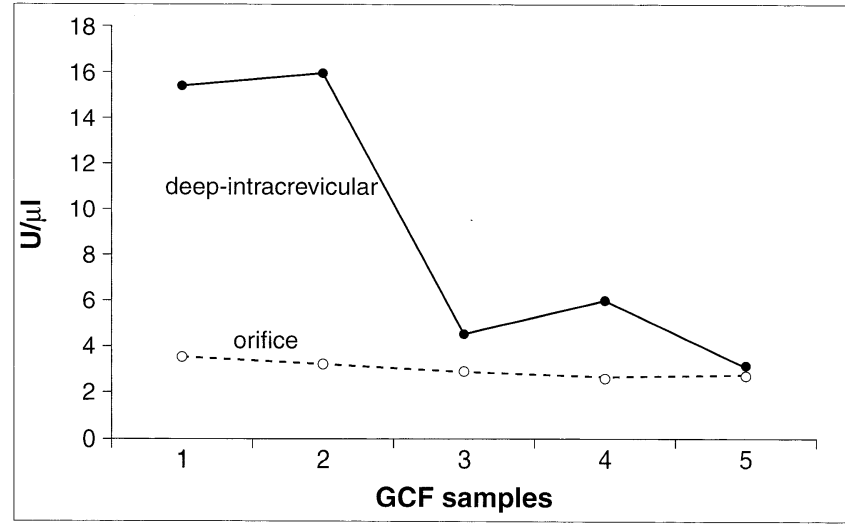

Fig. 2 Mean myeloperoxidase levels during repeated sampling presented as myeloperoxidase concentration. 
Total MPO activity: Descriptive statistical data regarding GCF total MPO activity and actual $\mathrm{t}$ and $\mathrm{p}$ values are given in Table 3 . For the orifice method, significant decreases in total MPO activity were observed in the 3rd and 4th samples $(P<0.05)$ when compared to initial sample. With the deep-intracrevicular technique, a gradual decrease in total MPO activity was observed during sequential sampling. When compared to the first sample, significantly lower total MPO activity was detected only in the 5th sample $(P<0.05)$. Deep-intracrevicular sampling provided significantly higher GCF total MPO activity than the orifice method $(P<0.05)$. For the last samples, the difference in total MPO activity between two methods were not significant $(t=1.752, P=0.09)$ (Fig. 3).

Correlations between $G C F$ volume/MPO activity: No consistent correlations could be seen between GCF volume and MPO activity with either of the sampling techniques. However, random correlations existed between GCF volume and total MPO activity. For the orifice method, GCF volume showed a strong positive and significant correlation with total MPO activity in the $2 \mathrm{nd}$ sample $(\mathrm{r}=0.628, P=$ 0.004), while for the deep-intracrevicular method, a strong, positive significant correlation between GCF volume and total MPO activity was seen in the first sample $(r=0.748$, $P=0.0001)$. No significant correlations between GCF volume and MPO concentration were detected $(P>0.05)$ (Table 4).

Table 2 Descriptive statical data regarding mean gingival crevicular fluid myeloperoxidase concentration during sequential sampling $(\mathrm{U} / \mu \mathrm{l})$

\begin{tabular}{|c|c|c|c|c|c|c|c|c|c|c|}
\hline & & \begin{tabular}{|c|} 
Arithmetical \\
mean
\end{tabular} & S.E.M. & $S . D$ & Minimum & Maximum & $\bar{t}$ & $\bar{p}$ & $\bar{t}$ & $\bar{p}$ \\
\hline \multirow{5}{*}{$\begin{array}{l}\text { Orifice } \\
\text { technique }\end{array}$} & $1^{\text {st }}$ Sample & 2.57 & 0.53 & 12.05 & 0.1 & 8 & & & & \\
\hline & $2^{\text {nd }}$ Sample & 2.14 & 0.47 & 18.51 & 0.01 & 8 & 1.434 & \begin{tabular}{|l|} 
\\
\end{tabular} & & \\
\hline & $3^{\text {rd }}$ Sample & 1.91 & 0.43 & 18.34 & 0.01 & 6.3 & 2.144 & $0.045^{* *}$ & & \\
\hline & $4^{\text {th }}$ Sample & 1.56 & 0.33 & 21.31 & 0.1 & 4 & 2.292 & $0.033^{* *}$ & & \\
\hline & $5^{\text {th }}$ Sample & 1.62 & 0.55 & 18.77 & 0.1 & 8.8 & 2.275 & $0.035^{*+1}$ & & \\
\hline \multirow{5}{*}{$\begin{array}{l}\text { Deep- } \\
\text { intracrevicular } \\
\text { technique }\end{array}$} & $1^{\text {st }}$ Sample & 15.29 & 7.77 & 32.95 & 0.5 & 135 & & & 1.725 & 0.093 \\
\hline & $2^{\text {nd }}$ Sample & 15.88 & 11.44 & 42.8 & 0.01 & 164 & 0.213 & \begin{tabular}{|l|l|} 
\\
\end{tabular} & 1.405 & 0.170 \\
\hline & $3^{r^{d}}$ Sample & 3.77 & 1.24 & 4.31 & 0.4 & 12.6 & 1.642 & \begin{tabular}{|l|}
0.129 \\
\end{tabular} & 1.680 & 0.103 \\
\hline & $4^{\text {th }}$ Sample & 5.65 & 2.92 & 10.12 & 0.5 & 36 & 1.506 & \begin{tabular}{|l|}
0.160 \\
\end{tabular} & 1.797 & 0.082 \\
\hline & $5^{\text {th }}$ Sample & 1.88 & 0.51 & 1.84 & 0.3 & 6.3 & 1.723 & \begin{tabular}{|l|}
0.111 \\
\end{tabular} & 0.331 & 0.743 \\
\hline
\end{tabular}

Table 3 Descriptive statical data regarding mean total myeloperoxidaseactivityduring sequential sampling (U)

\begin{tabular}{|c|c|c|c|c|c|c|c|c|c|c|}
\hline & & $\begin{array}{l}\text { Arithmetical } \\
\text { mean }\end{array}$ & S.E.M. & S.D & Minimum & Maximum & $\mathrm{t}$ & $\bar{p}$ & $t$ & $\bar{p}$ \\
\hline \multirow{5}{*}{\begin{tabular}{|l} 
Orifice \\
technique
\end{tabular}} & $1^{1^{5}} \mathrm{Sample}$ & 0.154 & 0.035 & 0.158 & 0.01 & 0.6 & & & & \\
\hline & $2^{\text {nd }}$ Sample & 0.153 & 0.048 & 0.21 & 0.01 & 0.7 & 0.020 & \begin{tabular}{|l|}
0.984 \\
\end{tabular} & & \\
\hline & $3^{\text {td }}$ Sample & 0.116 & 0.03 & 0.133 & 0.01 & 0.6 & 2.323 & $0.031^{1 * *}$ & & \\
\hline & $4^{\text {th }}$ Sample & 0.08 & 0.019 & 0.083 & 0.01 & 0.3 & 3.311 & $0.004^{* *}$ & & \\
\hline & $5^{\text {th }}$ Sample & 0.112 & 0.049 & 0.212 & 0.01 & 0.9 & 1.122 & 0.276 & & \\
\hline \multirow{5}{*}{$\begin{array}{l}\text { Deep- } \\
\text { intracrevicular } \\
\text { technique }\end{array}$} & $1^{\text {st }}$ Sample & 0.831 & 0.17 & 0.72 & 0.1 & 2.6 & & & 4.101 & $0.0001^{\star}$ \\
\hline & $2^{\text {nd }}$ Sample & 0.578 & 0.135 & 0.505 & 0.01 & 1.6 & 0.818 & 0.428 & 3.310 & $0.002^{*}$ \\
\hline & $3^{\text {td Sample }}$ & 0.449 & 0.093 & 0.322 & 0.01 & 0.8 & 1.418 & \begin{tabular}{|l|}
0.184 \\
\end{tabular} & 4.101 & $0.001^{*}$ \\
\hline & $4^{\text {th }}$ Sample & 0.37 & 0.127 & 0.44 & 0.1 & 1.5 & 1.919 & 0.081 & 2.891 & $0.007^{*}$ \\
\hline & $5^{\text {th }}$ Sample & 0.234 & 0.044 & 0.161 & 0.01 & 0.6 & 3.125 & $0.009+$ & 1.752 & 0.090 \\
\hline
\end{tabular}

* significant when compared to related orifice samples $(p<0.05)$

"* signiffant when compared to initial orifice sample $(p<0.05)$
t significant when compared to initial deep-intracrevicular sample $(p<0.05)$
Table 4 Correlations between gingival crevicular fluid volume and two modes of data presentation

\begin{tabular}{|c|c|c|c|c|c|c|}
\hline & & Mean Volume & & & $\mathrm{MPO}$ & ation \\
\hline \multirow{5}{*}{$\begin{array}{c}\text { Orifice } \\
\text { technique }\end{array}$} & $1^{\text {si }} \mathrm{S}$ molo & 1685 & 0.335 & $p$ & $\frac{r}{0.162}$ & $\frac{P}{0494}$ \\
\hline & $2^{\text {nd }}$ Sample. & 18.1 & 0.628 & $0.004^{* *}$ & 0.107 & 0.662 \\
\hline & $3^{\text {rd }}$ Sample & 20.75 & 0.312 & 0.18 & -0.093 & 0.696 \\
\hline & $4^{\text {th }}$ Sample & 19.2 & 0.261 & 0.266 & -0.216 & 0.36 \\
\hline & $5^{\text {th }}$ Sample & 23 & 0.221 & 0.363 & 0.19 & 0.436 \\
\hline \multirow{5}{*}{$\begin{array}{l}\text { Deep- } \\
\text { intracrevicular } \\
\text { technique }\end{array}$} & $1^{\text {st Sample }}$ & 53.2 & 0.748 & $0.0001^{* *}$ & -0.22 & 0.38 \\
\hline & $2^{\text {nd }}$ Sample & 67.8 & 0.234 & 0.422 & 0.279 & 0.335 \\
\hline & $3^{\text {rd Sample }}$ & 75.25 & 0.349 & 0.266 & -0.295 & 0.352 \\
\hline & $4^{\text {th }}$ Sample & 68.95 & 0.218 & 0.497 & -0.27 & 0.933 \\
\hline & $5^{\text {th }}$ Sample & 84.05 & 0.529 & 0.063 & -0.341 & 0.254 \\
\hline
\end{tabular}

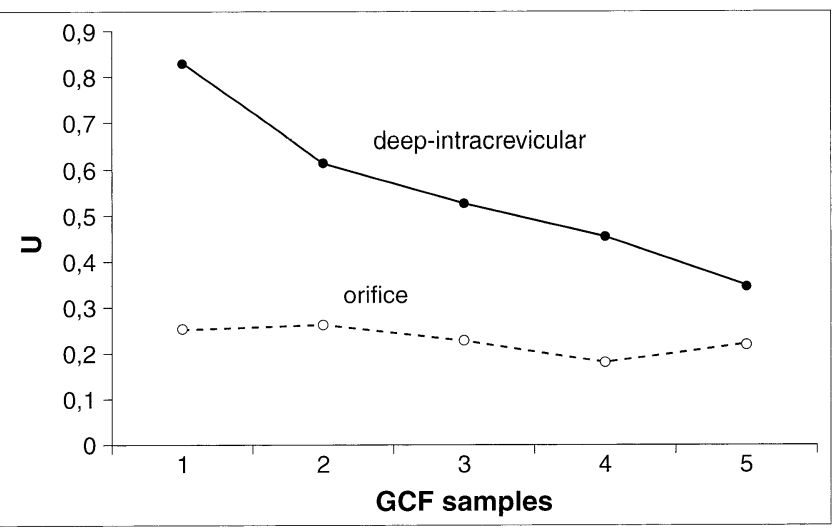

Fig. 3 Mean myeloperoxidase levels during sequential sampling presented as total myeloperoxidase activity.

Correlations between MPO concentration/total MPO activity: Correlations between GCF MPO concentration/total MPO activity are given in Table 5. For the orifice technique, there was a significant positive correlation between MPO concentration and total MPO activity in all of the 5 samples $(P<0.05, P<0.001)$. However, for the deep-intracrevicular method, such a correlation could only be observed in the 2 nd samples ( $\mathrm{r}$ $=0.638, P=0.014)$.

Correlations between GCF volume and clinical parameters: Significant correlations between mean GI GCF volume and mean PD-GCF volume were not observed $(P>0.05)$.

Table 5 Correlations between myeloperoxdase concentration and total myeloperoxidase activity

\begin{tabular}{|c|c|c|c|}
\hline & & $\bar{r}$ & $p$ \\
\hline \multirow{5}{*}{ Orifice technique } & $1^{\text {st }}$ Sample & 0.833 & $0.0001^{\text {*n }}$ \\
\hline & $2^{\text {nd }}$ Sample & 0.482 & $0.037^{*}$ \\
\hline & $3^{\text {td }}$ Sample & 0.739 & $0.0001^{* *}$ \\
\hline & $4^{\text {th }}$ Sample & 0.621 & $0.003^{* *}$ \\
\hline & $5^{\text {th }}$ Sample & 0.928 & $0.0001^{* *}$ \\
\hline \multirow{5}{*}{$\begin{array}{l}\text { Deep-intracrevicular } \\
\text { technique }\end{array}$} & ${1^{\text {st }} \text { Sample }}$ & 0.159 & 0.529 \\
\hline & $2^{\text {nd }}$ Sample & 0.638 & $0.014^{*}$ \\
\hline & $3^{\text {rd }}$ Sample & 0.509 & 0.091 \\
\hline & $4^{\text {th }}$ Sample & 0.200 & 0.532 \\
\hline & $5^{\text {th }}$ Sample & 0.067 & 0.828 \\
\hline
\end{tabular}




\section{Discussion}

Although symmetrical sampling sites had a similar clinical status, the deep-intracrevicular technique always provided higher amounts of GCF than the orifice method. This is in accordance with an early study of Egelberg and Attström (14) who reported greater amounts of GCF with the intracrevicular technique than the orifice technique, both in humans and dogs. For daily repeated samples, a gradual volumetric increase was observed with both techniques, but volumetric change was more prominent with the intracrevicular technique. These smaller volumes are not necessarily a disadvantage; rather the orifice technique might be preferable due to less volumetric variations. Our 10-minute sequential sampling interestingly provided similar volumetric results with this 4-day consecutive sampling model (14), since less fluctuations in GCF volume with the orifice technique was seen. When compared to baseline samples, GCF volume in the last samples increased by $37 \%$ with the orifice technique, while an increase by $58 \%$ was observed with the deepintracrevicular technique.

Contrary to the significantly increased GCF volume observed immediately after the first deep intracrevicular sampling, we observed nearly stable GCF volumes throughout the first 4 orifice samples (approximately 5 minutes). These findings clearly indicate that GCF volume is affected by the selected sampling technique. Besides providing larger amounts of GCF, the deep-intracrevicular technique also significantly increased GCF volume throughout sequential sampling. The main reason for this seems to be the intensity of inevitable mechanical irritation during strip placement deep into the base of the pocket, since GCF volume and flow rate is suggested to be influenced by vascular permeability and also by the method of collection $(1,10,14,18)$.

The effect of sequential sampling on GCF volume and composition has been evaluated in several studies with different time intervals $(1,8-10,13,14,16,28)$. Lamster et al. (16) reported minimal variation in volume in a repeated sampling protocol including 0, 4, 8, 30 and 60 minutes, but also demonstrated that volume was prominently affected by the clinical periodontal status with 5 minute sequential deep-intracrevicular sampling.

Griffiths et al. (10) reported great differences in GCF volume and flow rate among sampling sites and suggested that flow rate mainly depended on vascular permeability. They also suggested that the 5th samples obtained after a prolonged time could be less representative of native GCF and the method of collection could influence GCF flow rate. Curtis et al. (8), after placing the strips at the entrance of crevice, reported the highest GCF volume in the first samples, however they also demonstrated a significant increase in GCF volume in 5th samples obtained at the end of 10 minutes. On the contrary, we found the highest GCF volume in the last samples with both sampling techniques. This discrepancy could be due to the sampling of GCF from periodontally-healthy adolescents in the former study (8). However, in the last (5th) samples, GCF volume was found to be significantly increased in both of the studies. This increase can be attributed to the additional sampling time, which could lead to a building up of a larger volume of freshly formed fluid (8) and also to the mechanical effect of the previous four sampling attempts, regardless of the technique.

It was shown that during repeated sampling, GCF volume could stay stable within 5-10 minutes, however increased $20 \%$ with time $(1,28)$. Our findings demonstrating a volumetric increase with both sampling techniques are generally in accordance with the time-limited stability of GCF $(1,28)$. However, this stability could only be achieved with the orifice method. Thus, we may further suggest that the volumetric stability of GCF during sequential sampling also depends upon the selected sampling technique. The volumetric stability of the orifice technique cannot be expected with the deep intracrevicular technique, mainly due to the increased risk of mechanical irritation $(10,14)$.

The quantity of various GCF constituents, including aspartate aminotransferase $(9,13)$, lactate dehydrogenase (13), total protein (8), elastase (29), collagenase $(12,30)$ and acid and alkaline phosphatases (4) are also shown to be affected by sequential sampling performed with various time intervals. The highest aspartate aminotransferase $(9,13)$, lactate dehydrogenase (13) and cytoplasmic and lysosomal enzyme activities (16) were demonstrated in the first GCF samples and significant reductions were observed with subsequent sampling $(9,13,16)$. For the analysis performed on the last 2 of 3 sequential samplings, GCF flow rate and elastase activity was shown to be increased with the severity of gingival inflammation. Furthermore, enzyme activity was found to be diluted by the increased GCF volume and GCF flow rate was suggested to be primarily dependent on vascular permeability (29). Villela et al. (12) demonstrated a constant flow rate and collagenase concentration throughout 5 consecutive 3-minute samplings. However, daily variations in GCF volume and collagenase activity was reported in a 26-week study (30). When GCF was collected 6 times over a 6 -week period, GCF volume and enzyme activity were found to vary from sample to sample. The mean range of GCF volume among sites was shown to be greater than the range of enzymes and a greater variation among sites than quantity 
of PMNs migration was suggested (5). Binder et al. (4) demonstrated that GCF volume and acid and alkaline phosphatase responded uniquely to sequential sampling. The highest GCF volume was observed in the first samples and showed minimal changes afterwards. When the data were presented as enzyme concentration or total enzyme activity, the highest total acid phosphatase activity was observed in the first samples and decreased throughout 5 subsequent sampling attempts. Lamster et al. (16) demonstrated that GCF volume varied minimally with sequential sampling, however a general reduction was detected in the analyzed lysosomal enzymes.

The higher enzymatic activity of the first samples was primarily attributed to the reservoir activity within the sulcus/pocket $(4,9,13,16)$. Furthermore, GCF volume in the crevice was suggested to recover more rapidly than hostoriginated GCF components (16) and 10 minute was not enough time for most GCF enzymes to replenish to their original levels $(9,13)$. Our findings regarding GCF MPO activity are generally in accordance with most of the previous studies demonstrating a higher enzyme activity in rGCF samples $(4,9,13,16)$. Thus, our data also support the reservoir activity of MPO within the sulcus/pocket $(4,9,16)$ and are generally consistent with a depletion of host-originated enzymes from the sulcus/pocket with sequential sampling $(4,9,16)$.

Appropriate mode of data presentation for GCF MPO activity was another concern of the present study. Thus, GCF MPO activity was presented both as total MPO activity and MPO concentration. Our findings suggested that total MPO activity and MPO concentration were not absolutely matching measures and were also affected by the sampling technique. Throughout the 5 consecutive samplings, MPO concentration presented no significant differences between the orifice and deep intracrevicular techniques. However, the difference between the two techniques regarding total MPO activity was statistically significant for the first samples. Contrary to the general tendency for MPO concentration to decrease with subsequent orifice samplings, MPO concentration showed no significant differences during sequential intracrevicular samplings. On the other hand, during repeated samplings with both techniques, total MPO activity significantly decreased. These findings may suggest that the two modes of data presentation were uniquely affected, both by the sampling technique and sequential sampling attempts. With the sequential orifice samples there was a general tendency for MPO to decrease with either modes of the data presentation. However, when the deep-intracrevicular technique and MPO concentration were preferred, data was unstable during repeated samples.
MPO activity in GCF is suggested to mainly reflect the quantity of PMN influx (22). Smith et al. (22) revealed that GCF MPO activity showed a weak relationship with increased GCF volume and suggested that GCF MPO did not reflect volumetric changes, but rather was related with the characteristics of the lesion. In the present study, during sequential sampling, a general decrease in total MPO activity was observed despite volumetric fluctuations. Therefore, we support the previous suggestions that GCF flow and PMN migration to the crevice act as distinctly different entities $(15,31)$ and GCF depleted from the sulcus/pocket seems to recover more rapidly than hostoriginated components (16). Furthermore, the lack of an absolute correlation between volume and MPO activity may also confirm that GCF flow and host-originated enzymatic content of GCF are independently regulated $(15,31)$.

In brief, the findings of the present study suggest that selection of sampling technique, sequential sampling and data presentation are critical methodological decisions since they all may have a significant effect on the actual GCF enzymatic profile.

\section{References}

1. Cimasoni, G. (1983) Crevicular fluid updated. In Monographs in oral science. Vol.12, Myers,H.M. ed., 2 nd ed., Karger, Basel, 29-44

2. Lamster, I.B., Hartley, L.J. and Vogel, R.I. (1985) Development of a biochemical profile for gingival crevicular fluid. Methodological considerations and evaluation of collagen-degrading and ground substance-degrading enzyme-activity during experimental gingivits. J. Periodontol. 56 (Supple.), 13-21

3. Lamster, I.B., Oshrain, R.L. and Gordon, J.M. (1986) Enzyme activity in human gingival crevicular fluid: considerations in data reporting based on analysis of individual crevicular sites. J. Clin. Periodontol. 13, 799-804

4. Binder, T.A., Goodson, J.M. and Socransky, S.S. (1987) Gingival fluid levels of acid and alkaline phosphatase. J. Periodontal. Res. 22,14-19

5. Smith, Q.T. and Geegan, S.J. (1991) Repeated measurement of crevicular fluid parameters at different sites. J. Clin. Periodontol. 18, 171-176

6. Gustafsson, A., Åsman, B. and Bergström, K. (1994) Elastase and lactoferrin in gingival crevicular fluid: possible indicators of a granulocyte-associated specific host response. J. Periodontal. Res. 29, 276282

7. Hancock, E.B., Cray, R.J. and O' Leary, T.J. (1979) The relationship between gingival crevicular fluid 
and gingival inflammation. A clinical and histologic study. J. Periodontol. 50, 13-19

8. Curtis, M.A., Griffiths, G.S., Price, S.J., Coulthurst, S.K. and Johnson, N.W. (1988) The total protein concentration of gingival crevicular fluid. Variation with sampling time and gingival inflammation. J. Clin. Periodontol. 15, 628-632

9. Persson, G.R. and Page, R.C. (1990) Effect of sampling time and repetition on gingival crevicular fluid and aspartate aminotransferase activity. J. Periodontal. Res. 25, 236-242

10. Griffiths, G.S., Sterne, J.A.C., Wilton, J.M.A., Eaton, K.A. and Johnson, N.W. (1992) Associations between volume and flow rate of gingival creviccular fluid and clinical assessments of gingival inflammation in a population of British male adolescents. J. Clin. Periodontol. 19, 464-470

11. Rüdin, H.J., Overdýek, H.F. and Rateitschak, K.H. (1970) Correlation between sulcus fluid rate and clinical and histological inflammation of the marginal gingiva. Helv. Odontol. Acta 14, 21-26

12. Villela, B., Cogen, R.B., Bartolucci, A.A. and Birkedal-Hansen, H. (1987) Crevicular fluid collagenase activity in healthy, gingivitis, chronic adult periodontitis and localized juvenile periodontitis patients. J. Periodontal. Res. 22, 209211

13. Atici, K., Yamalik, N., Eratalay, K. and Etikan, I. (1998) Analysis of gingival crevicular fluid intracytoplasmic enzyme activity in patients with adult periodontitis and rapidly progressive periodontitis. A longitudinal study model with periodontal treatment. J. Periodontol. 69, 11551163

14. Egelberg, J. and Attström, R. (1973) Comparison between orifice and intracrevicular methods of sampling gingival fluid. J. Periodontal. Res. 8, 384388

15. Kowashi, Y., Jaccard, F. and Cimasoni, G. (1980) Sulcular polymorphonuclear leucocytes and gingival exudate during experimental gingivitis in man. $\mathrm{J}$. Periodontal. Res. 15, 151-158

16. Lamster, I.B., Harper, D.S., Goldstein, S., Celenti, R.S. and Oshrain, R.L. (1989) The effect of sequential sampling on crevicular fluid volume and enzyme activity. J. Clin. Periodontol. 16, 252-258

17. Eley, B.M. and Cox, S.W. (1992) Cathepsin B/L-, elastase-, tryptase-, trypsin- and dipeptidyl peptidase IV-like activities in gingival crevicular fluid: correlation with clinical parameters in untreated chronic periodontitis patients. J. Periodontal. Res.
27, 62-69

18. Lamster, I.B., Oshrain, R.L., Fiorello, L.A., Celenti, R.S. and Gordon, J.M. (1988) A comparision of 4 methods of data presentation for lysosomal enzyme acticvity in gingival crevicular fluid. J. Clin. Periodontol. 15, 347-352

19. Cox, S.W. and Eley, B.M. (1992) Cathepsin B/L-, elastase-, tryptase-, trypsin- and dipeptidyl peptidase IV-like activities in gingival crevicular fluid. A comparison of levels before and after basic periodontal treatment of chronic periodontitis patients. J. Clin. Periodontol.19, 333-339

20. Boutros, S.M., Michalowicz, B.S., Smith, Q.T. and Aeppli, D.M. (1996) Crevicular fluid enzymes for endosseous dental implants and natural teeth. Int. J. Oral Maxillofac. Implants 11, 322-330

21. Klebanoff, S.J. (1968) Myeloperoxidase-halidehydrogen peroxide antibacterial system. J. Bacteriol. 95, 2131-2138

22. Smith, Q.T., Hinrichs, J.E. and Melnyk, R.S. (1986) Gingival crevicular fluid myeloperoxidase at periodontitis sites. J. Periodontal. Res. 21, 45-55

23. Löe, H. and Silness, J. (1963) Periodontal disease in pregnancy. I. Prevalence and severity. Acta Odontol. Scand. 21, 533-551

24. Brill, N. (1962) The gingival pocket fluid. Studies of its occurrence, composition and effect. Acta. Odontol. Scand. 20, Suppl. 32. 9-132

25. Demirpençe, E., Köksoy, C., Kuzu, A. and Kilinç, K. (1997) A spectrophotometric assay for tissueassociated myeloperoxidase activity and its application to intestinal ischemia- reperfusion. Turk. J. Med. Sci. 27, 197-200

26. Suzuki, K., Ota, H., Sasagawa, S., Sakatani, S. and Fujikura, T. (1983) Assay method for myeloperoxidase in human polymorphonuclear leucocytes. Anal. Biochem. 132, 345-352

27. Cohen, L. and Holliday, M. (1982) Statistics for social scientists. 2nd ed. Harper \& Row., London, 145-230

28. Darany, D.G., Beck, F.M. and Walters, J.D. (1992) The relationship of gingival fluid leukocyte elastase activity to gingival fluid flow rate. J. Periodontol. 63, 743-747

29. Mann, W.V. (1963) The correlation of gingivitis pocket depth and exudate from the gingival crevice. J. Periodontol. 34, 379-387

30. Birkedal-Hansen, H., Pierson, M., Heaven, T., Jeffcoat, M. and Cogen, R.B. (1989) Bone loss, GCF collagenase and GCF flow in human periodontitis. J. Dent. Res. 68, Special Issue,334 
(abstract)

31. Golub, L.M., Iacono, V.J., Nicoll, G., Ramamurthy, N. and Kaslick, R.S. (1981) The response of human sulcular leucocytes to a chemotactic challenge. A new in vivo assay. J. Periodontal. Res. 16, 171-179 